\title{
Improving the technical and economic efficiency of the Reservoir Pressure Maintenance system (RPM)
}

\author{
Sh.Sh. Zaurbekov \\ Doctor of Economics, Professor, Vice-Rector, Grozny State Oil Technical University named after Acad. M. \\ D. Millionschikov, Grozny, Russia \\ M.M. Labazanov \\ Ph.D., Head of Scientific and Technical Center "Nedra", Grozny State Oil Technical University named \\ after Acad. M.D. Millionschikov, Grozny, Russia \\ P.U. Musaeva \\ Laboratory Assistant, ILGGP Scientific and Technical Center Nedra, Grozny State Oil Technical Univer- \\ sity named after Acad. M.D Millionshchikov, Grozny, Russia
}

Z.I. Gadaeva

Head of the laboratory "ILGGP” NTC "Nedra", Grozny State Oil Technical University named after Acad. M.D. Millionschikov, Grozny, Russia

T.Kh. Ozdieva

Head of the laboratory "ILGEM" NTC "Nedra", Grozny State Oil Technical University named after Acad. M.D. Millionschikov, Grozny, Russia

I.R. Masarov

Assistant driller, production and exploration wells for oil and gas of the 5th category, Tomsk, Russia

Damzaev

Junior Researcher, Scientific and Technical Center "Nedra", Grozny State Oil Technical University named after Acad. M.D. Millionschikov, Grozny, Russia

ABSTRACT: Waterflooding of oil fields is undoubtedly the most effective way to develop them, providing high rates of oil recovery, significant periods of well flowing and an increase in oil recovery coefficient. Suffice it to say that $95 \%$ of all oil produced in the country is accounted for by fields developed using various modifications of waterflooding systems. At the same time, the amount of water pumped into the reservoirs on average doubles the volume of the selected oil.

Naturally, such volumes of injection are associated with huge investments and operating costs, determined by the need to drill injection and water wells, the construction of water intakes, pumping stations, long-term pressure pipelines, commissioning of sewage treatment plants, etc.

So, for example, 381 injection wells were drilled at one of the largest oil fields in the country - Mamontovskoye, 20 water wells from which Apt-Cenomanian water was extracted mechanically, 17 cluster pumping stations were built, each of which owed 7-10 bushes.

The total length of high-pressure pipelines in the field is $656 \mathrm{~km}$. The vast majority of the country's oil fields are equipped with similar RPM systems. The functioning and maintenance of such a complex economy is associated with the large operational costs of small oil production resources should be an increase in the technical and economic efficiency of the reservoir pressure maintenance system. The aforementioned will be caused by an increase in the injectivity of injection wells associated with a decrease in viscosity, both when using directly thermal water for flooding, and when heating injected surface water due to deep heat. 
Such an increase in the acceptability of injection wells allows decreasing wellhead injection pressures while maintaining injection volumes, or increasing injection volumes while maintaining these pressures, or reducing the number of injection wells while maintaining wellhead pressures and injection volumes.

\section{INTRODUCTION}

The most important task in the development and operation of oil fields is the maximum extraction of oil from productive formations. As was shown, the completeness of oil recovery from the reservoirs is characterized by the reservoir recovery coefficient, which varies widely over different fields. Various methods are used to maintain reservoir pressure and increase the coefficient of reservoir recovery, but methods such as injection of water or gas under pressure into productive formations have found the greatest application in practice. (Ozdoeva, Labazanov, Shaipov, Damzaev, 2017).

A system for maintaining reservoir pressure is the process of naturally or artificially maintaining pressure in productive formations of oil deposits at the initial or projected value in order to achieve high rates of oil production and increase the degree of oil recovery. The RPM system during the development of an oil reservoir can be implemented due to the natural active water pressure or water pressure elastic mode, artificial water pressure created as a result of injection of water into reservoir reservoirs during outflow or outflow, as well as during outflow flooding. Depending on the geological conditions and economic development indicators, one or another method of PPD or a combination of them is chosen.

For many decades of development of the oil industry, field development was carried out by drilling only production wells and extracting oil from them through the use of resources of all natural types of reservoir energy. After depletion of reservoir energy and a decrease in bottomhole pressure in production wells, sometimes fields were abandoned to zero when extracting no more than $25-30 \%$ of the initial oil reserves in the reservoir.

Artificial water flooding is widespread. At the fields developed with flooding, about $90 \%$ of the total oil production is currently produced, more than 2 billion $\mathrm{m} 3$ per year is pumped into the reservoirs. The popularity of artificial waterflooding of oil deposits is due to its following advantages:

- availability and free water;

- the relative simplicity of water injection;

- relatively high efficiency of oil displacement by water.

Initially, the use of water flooding was mainly associated with the injection of water into injection wells located in the marginal part of the field (marginal flooding). The principles of near-water flooding - multi-stage development, transfer of injection, shut-off of low-water wells and others - are not widespread. (Shupik 2013).

At present, block systems of in-circuit flooding are justified. With these systems, it is necessary to cut the oil field into blocks of optimal sizes, which exclude the conservation of oil reserves in the inner zones.

The oil industry at the present stage is the most powerful and highly efficient consumer of thermal waters, although for unknown reasons the volumes of thermal waters used in oil production are not taken into account when assessing the consumption of geothermal energy in the country as a whole.

With the use of water flooding, more than 350 fields are developed, providing $96 \%$ of the country's total oil production. Water flooding is the main method of developing oil fields. This allows the country to ensure the highest level and rate of oil production in the world.

In recent years, certain difficulties have been outlined in the development of the oil industry, a tendency to reduce the technical and economic indicators of field development, and the pace of development of the industry.

These difficulties and trends are due to modern features of the industry, the main of which can be summarized as follows: 
- The deterioration of the structure of reserves, which occurs both in the developed fields, due to their natural depletion and the accelerated development of highly productive parts, and in new fields due to the fact that the latter are characterized by low permeability of reservoirs, high viscosity of oil, high paraffin content in it, small oil-saturated thicknesses, occurrence of oil in the sub-gas parts and oil-water zones, etc. The above complicates the development process, leads to a decrease in oil recovery rates and oil production rates, requires an increase in the efficiency of existing development systems, the use of more active systems with tight well networks in new fields, necessitates the maintenance of not only reservoir pressure, but also temperature, and the use of new, more complex and expensive technologies, etc.

- Depletion and flooding of the country's main developed fields. Almost all of the large fields that provide the main oil production have entered the late stage of development. The commissioning of new capacities in the industry in recent years has been mainly spent on compensating for the increasing losses of production in fields entering the late stage of development, which are characterized by a significant drop in oil production, a rapid increase in water cut in well production, and the transfer of almost the entire stock to mechanized methods of raising the liquid, retirement of some of them from operation, increase in flow rates of wells by fluid, and withdrawal of fluid from the entire facility.

Due to the depletion and watering of the main developed fields from 1980 to 2010. there was an increase in the average water cut of well production from 57.5 to 74.6 , a water-oil factor from 1.35 to 2.91 , a decrease in fountain production from $45 \%$ to $25-30 \%$, an increase in the mechanized well stock from 64.4 to 149.9 thousand., an increase in the volume of injected water from 1.400 to 2 billion $\mathrm{m}^{3}$.

Field development under these conditions often requires a number of such capital-intensive technological and technical measures to further intensify the development and involve previously uncovered, worse in productivity and operating conditions parts of the deposits, such as additional cutting, creating foci of waterflooding, the transition to areal systems, the formation of fluid withdrawals from individual wells and fields, changing the direction of formation flows, conducting insulating work, etc.

The implementation of these measures requires the drilling of a significant number of additional wells, reconstruction of field facilities, waterflooding capacities, oil treatment and utilization of associated water, and energy re-equipment of the fields.

- Increasing the depth of well drilling in both the "old" and relatively new areas of oil production. Prospects for oil production, especially in the "old" oil producing areas, are associated with access to great depths (about 6000-7000 m). Deposits at these depths are characterized by high initial formation pressure and temperature, a high content of corrosive components (sulfur, hydrogen sulfide, carbon dioxide) in the formation fluids, and the possible manifestation of the plastic properties of oil-bearing rocks. The aforementioned features pose great challenges for science and industry in creating special methods for developing such deposits, and for the necessary drilling and technological equipment.

- A sharp increase in the stock of injection and production wells, especially requiring the use of more labor-intensive and expensive mechanized methods of operation.

- Relocation of the main volumes of oil production to areas with severe climatic conditions. If in 1990 these areas accounted for only about half of the country's oil production in 2010, more than $2 / 3$ of all production falls on these areas. With the aforementioned half-time increase in the stock of producing wells in the country as a whole, a three-fold increase is expected in these areas. The development of oil fields and the operation of wells under these conditions are associated with significant expenditures of fuel and energy resources for own needs. It is clear that the above main features of the current state of oil field development lead to a decrease in the efficiency of their development processes, technical and economic indicators of the development of the industry as a whole. The indicated tendency for their regular decrease is likely to continue in the future. Under these conditions, any positive step towards increasing the marked indicators will be a significant contribution to 
solving the most important tasks of the energy program. (Shaipov, Labazanov, Batukaev, Gadaeva, Damzaev, 2017).

In addition to injecting water or gas into the reservoirs, other methods of maintaining reservoir pressure are also used in practice: treating the injected water with surface-active substances (surfactants), injecting carbon dioxide into the reservoirs, and thermal methods. The use of surfactants for additives in injected water in small quantities (0.05-0.1\%) significantly reduces the surface tension at the border with oil and with a solid rock surface, reduces the necessary pressure drop for moving oil through the capillaries and contributes to better leaching of oil from the capillaries. According to laboratory studies, oil recovery when using surfactants can increase by $15-16 \%$.

One of the possible ways to maintain reservoir pressure, increase the efficiency and technical and economic indicators of oil field development is to more actively engage and use for this purpose thermal water resources, huge reserves of which are concentrated in the areas where oil production is located, especially in the Tersko-Sunzhenskoye oil and gas region. Some of the promising features of this method of reservoir pressure maintenance are described in this article.

The initial value of the reservoir temperature and its distribution are determined by the geothermal conditions in which the field is located. Typically, the reservoir temperature of oil fields corresponds to the geometric mean gradient in a given geological region. However, significant deviations of formation temperature from this value are also observed. Then it is believed that the reservoir temperature is increased or decreased. High temperature crust zones are called geothermal zones. (Grattoni Carlos, 2003).

In the process of developing an oil field, its reservoir temperature can change significantly. This occurs when substances, mainly water, are injected into the formation with a different temperature than the initial formation, as well as during exothermic reactions in the formation. To a much lesser extent, the reservoir temperature changes due to the throttling of the extracted liquids and gases and hydraulic friction against the formation rocks of the substances filtered in it.

The distribution of reservoir temperature underground and its change in time is called the temperature regime of the field. Temperature changes in oil reservoirs occur mainly due to thermal conductivity and convection.

Oil reservoirs are not thermally insulated from surrounding rocks and from other reservoirs. Therefore, any change in temperature in any section compared to other sections entails its redistribution and heat transfer due to thermal conductivity. The injection into the reservoir of water with a different temperature than the reservoir, and the extraction of oil from the reservoir with reservoir temperature lead to a change in the heat content in the reservoir and, consequently, the reservoir temperature.

Consider the process of oil displacement by water from a homogeneous rectilinear reservoir under conditions when the injected water has a different temperature than the reservoir. For simplicity, we assume that the displacement of oil by water is reciprocating, and the residual oil saturation decreases with increasing temperature according to a certain law.

An increase in the injectivity of the injection well with a decrease in the viscosity of the injected water follows from Darcy's law.

A significant decrease in the viscosity of water with increasing temperature, especially in the range of relatively low reservoir temperatures, causes a significant effect of this factor on the filtration resistance of the bottom-hole zone of the well. The dependence of the viscosity of mineralized water $\mu \mathrm{v}$ on temperature is quite accurately described by the following empirical formula:

$$
\mu_{v}=\left(35+0.7 M+0.22 M^{2}\right) /(+15.7)
$$

where $\mathrm{T}$ and $\mathrm{M}$ are the temperature and salinity of the water for which the viscosity value is determined.

Bottom water temperature is a function of flow rate, deep wells, geothermal gradient, wellhead temperature, etc. Theoretical assumptions and experience in thermal and per well shows 
that at fairly high costs in excess of $300-400 \mathrm{~m}^{3} /$ day. The change in water temperature along the wellbore at steady state is about $3^{\circ} \mathrm{C} / 1000 \mathrm{~m}$ depthTherefore, without resorting to complex solutions of the heat transfer equations in the wellbore, to assess the increase in injectivity of the well, we take the dependence of the bottomhole temperature in the injection well (with an average depth of $3000 \mathrm{~m}$ ) on its value at the wellhead, in the following simple form:

$$
t_{c}=t_{y}+10
$$

where $t_{c}$ and $t_{y}$ are the temperature of the injected water at the bottom and at the mouth.

Then, for the axisymmetric flow in the near-well zone of the injection well, for the flow rates of the wellhead temperatures $t_{\mathrm{y} 1}$ and $\mathrm{t}_{\mathrm{y} 2}$, one can obtain:

$$
\frac{\mathrm{q}_{2}}{\mathrm{q}_{1}}=\frac{\frac{1}{\mathrm{t}_{\mathrm{y}}+25.7} \ln \frac{10}{\mathrm{r}_{\mathrm{c}}}+\frac{1}{\mathrm{t}_{\mathrm{p}}+15.7} \ln \frac{\mathrm{R}_{\mathrm{k}}}{10}}{\frac{1}{\mathrm{t}_{\mathrm{y}}+25.7} \ln \frac{10}{\mathrm{r}_{\mathrm{c}}}+\frac{1}{\mathrm{t}_{\mathrm{p} 1}+15.7} \ln \frac{\mathrm{R}_{\mathrm{k}}}{10}}
$$

where $\mathrm{q}_{2}$ and $\mathrm{q}_{1}$ are flow rates at temperatures ty $\mathrm{y}_{1}$ and $\mathrm{ty}_{2} ; \mathrm{Rk}$ and $\mathrm{r}_{\mathrm{c}}$ are the radii of the drainage zone and the well; $\mathrm{t}_{\mathrm{pl}}$ - reservoir temperature.

When deriving formula (3), it was assumed that the radius of the zone around the bottom of the injection well cooled to a temperature $t_{c}$ is $10 \mathrm{~m}$.

The results of estimates for $R_{k}=500$ and $r_{c}=0.1 \mathrm{~m}$ at reservoir temperatures of 80 and $120^{\circ} \mathrm{C}$ (Figure 1).

The calculations were performed for the ranges of temperature changes of cold and hot (thermal) water characteristic of the conditions of deposits in Western Siberia. From the graph it follows that the increase in flow rate due to the injection of water at a higher temperature depends on the absolute values of wellhead temperatures.

So, for example, if, as a result of injection, thermal waters instead of normal, the temperature on the spine rises from four to $20^{\circ} \mathrm{C}$ at a reservoir temperature of $80^{\circ} \mathrm{C}$, the injectivity increases by $35 \%$. In the case of lifting and pumping thermal Cenomanian water through the same well, due to a decrease in heat loss during the transport of water, we can assume that a temperature of about $45^{\circ} \mathrm{C}$ is provided at the mouth.

With an increase in the water temperature at the wellhead from 4 to $45^{\circ} \mathrm{C}$ at a reservoir temperature of $80^{\circ} \mathrm{C}$, the injectivity of the well increases by $85 \%$. Thus, an increase in the injectivity of injection wells as a result of an increase in the temperature of the injected water (due to the transition to the injection of thermal water instead of the usual one), contributes to

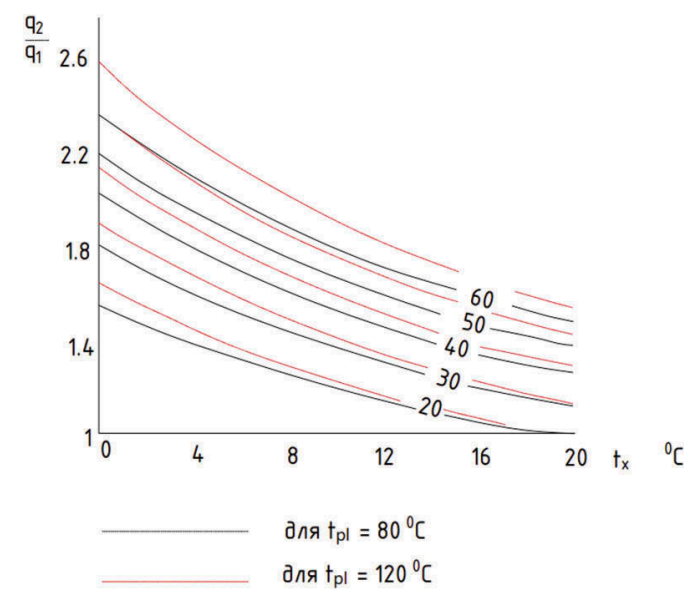

Figure 1. The dependence of the relative increase in the flow rate of the injection well from changes in the temperature of the injected water. 
a significant improvement in the technical and economic indicators of the pressure maintenance systems.

The increase in the technical and economic efficiency of RPM systems during the transition to thermal waterflooding, instead of the usual one, is largely associated with the acceleration of the development of RPM systems, with the exception or postponement of large investments in the construction of water intakes, structures and low pressure water pipelines at a later date.

In addition to the noted effects, the transition to flooding with warmer thermal water or surface water heated by deep heat will significantly reduce the pressure loss when pumping water from the pumping station to the bushes. In Western Siberia, pressure losses in high pressure waterways (3-10 km long), especially in winter, reach $15-30 \mathrm{~kg} / \mathrm{cm}^{2}$. Increasing the temperature of the water used for waterflooding is also important for the reliable operation of RPM systems at low temperatures. The noted significant reduces the likelihood of accidents associated with freezing of the mouths in the injection wells of their shafts in the intervals of permafrost distribution.

One of the promising directions of increasing the efficiency of waterflooding is the injection of formation water without lifting them to the surface. A well-known type of such injection is the transfer of water from water reservoirs into a drained oil reservoir. The simplicity of the technology and the exclusion of the aforementioned high costs associated with all ground structures of the RPM systems make this method especially valuable. However, the low filtration characteristics of real reservoir systems, the relatively small pressure differences created by the bypass and the hydrodynamic imperfection of the wells usually determine insufficient volumes of bypassed water. (Gabitov, Safonov, Strizhnev 2005).

The efficiency of the bypass in these cases can be significantly increased by taking measures to increase the pick-up coefficient.

In addition to the noted cost savings associated with the surface structures of the RPM system, it is obvious that in this case all the advantages that are characteristic of flooding the formations with thermal water are retained.

An even more promising and perfect method of flooding without raising the thermal formation water to the surface is the forced downhole pumping of water from the thermal formation into the oil one.

This method is based on the use of submersible pumps of the required capacity, installed directly in the wellbore in such a way as to take the required amount of water from the thermal reservoir and pump it into the water-filled oil reservoir.

Despite the lack of reliable experimental research in downhole injection, it can be assumed that this method, due to its great advantages, will find wide application in the near future.

\section{CONCLUSION}

The use of formation water instead of surface water, in addition to the listed advantages, allows saving large volumes of fresh water used for PPD systems. There is a shortage of fresh water in many, especially in the newly developed oil producing regions of Western Kazakhstan, the Caspian lowland, and Central Asia. Providing these areas with fresh water is associated with the laying of water pipelines of considerable length.

The volumes of water used to maintain reservoir pressure, as noted above, are huge. So, for example, at one of the largest oil fields of the Soyuz-Mamontovskoye, the annual injection in 1981 reached 49 million $\mathrm{m}^{3}$ (or 160,000 $\mathrm{m}^{3} /$ day). At the same time, 10 million $\mathrm{m}^{3}$ of Apt-Cenomanian reservoir water, about 5 million $\mathrm{m}^{3}$ of wastewater and about 35 million $\mathrm{m}^{3}$ of fresh water are ending. In total, since 1975, about 252 million $\mathrm{m}^{3}$ were pumped, of which 150 million $\mathrm{m}^{3}$ are fresh water. Even larger injection volumes are characterized by the largest oil field - Samotlor.

Currently, water injection at this field has reached 1.5 million $\mathrm{m}^{3} /$ day.

Obviously, the maximum use of thermal water instead of fresh water from surface sources, at such a scale of water flooding, saves huge amounts of fresh water.

It is known that both water from surface sources and associated water must be treated at special facilities before injection into oil reservoirs in order to reduce the content of solids and prevent infection of the reservoirs with sulfate-reducing bacteria 
This is associated with significant costs due to the need to use expensive equipment, scarce antiseptics and other reagents.

The use of formation water in the PPD system is usually possible without chemical treatment and purification. For example, for flooding productive formations of oil fields in Western Siberia, thermal waters of powerful water complexes of Apt-Cenomanian and Alb-Cenomanian deposits are used, which lie above productive horizons.

In terms of their physicochemical properties, these waters are close to the waters of productive formations; their displacement does not lead to the formation of precipitation and a decrease in the injectivity of injection wells; they do not require treatment and construction of treatment facilities. One of the drawbacks of surface water sources used for water supply to oil production is the development of microorganisms and algae in the bottom-hole zone of injection wells. In this case, sulfate-reducing bacteria pose the greatest danger. Propagation of these bacteria in the formation leads to the formation of sulfate ions $\left(\mathrm{SO}_{4}{ }^{-}\right)$, clogging the formation as a result of the activity of these bacteria in the formation, sulfides (FeS) are also formed, which in turn react with free iron. In this case, iron sulfide $\mathrm{FeS}$ itself is a blocking agent, and the hydrogen sulfide $\mathrm{H}_{2} \mathrm{~S}$, which is formed in this case, is a corrosive agent. The noted negative factors are completely eliminated when deep thermal formations are injected into the injection wells of thermal waters.

\section{REFERENCES}

Farkhutdinov A.M., Khamitov I.Sh., Cherkasov S.V., Mintsaev M.Sh., Zaurbekov Sh.Sh., Shaipov A. A., Labazanov M.M. 2017. Thermal groundwater of the East Ciscaucasia artesian basin: economic aspects of use on the example of the Khankalsky deposit. Tomsk. News of Tomsk Polytechnic University. Geo-Resource Engineering.

Gabitov G.Kh., Safonov E.H., Strizhnev V.A. and others. 2005. Improving the reservoir pressure maintenance system is the basis of the effective development of an oil field. Moscow. Oil industry.

Grattoni Carlos (Great Britain). 2003. Alternate water and gas injection, gas injection: Proceedings of the 12th European Symposium Enhancing Oil Recovery. Moscow.

Gumerov A.G., Bazhaikin S.G., Bagmanov A.A. and other. 2006. The technique of choosing pumping equipment for pumping water into the reservoir in the reservoir pressure maintenance system. Moscow. Enterprise Standard.

Edited by Kozlovsky E.A. 2001. Mountain encyclopedia. Moscow. Soviet Encyclopedia.

Lysenko V.D., Graifer V.I. 2001. Development of unproductive oil fields. Moscow. Nedra-Business Center LLC.

Ozdoeva L.I., Labazanov M.M., Shaipov A.A., Damzaev Z.M.E. 2017. The oil and gas potential of some areas in the Chechen Republic is promising. Grozny. In the collection: GEOTECHNOLOGIES OF THE XXI CENTURY Materials of the All-Russian Scientific and Practical Conference dedicated to the 100th anniversary of FSBEI HE "GSTU named after Acad. M.D. Millionschikova". Grozny State Oil Technical University named after academician M.D. Millionschikova.

Shaipov A.A., Labazanov M.M., Batukaev A.A., Gadaeva Z.I., Damzaev Z.M.E. 2017. Prospects for the development of thermal deposits in the Chechen Republic. Grozny. In the collection: FUNDAMENTAL AND APPLIED RESEARCH: PROBLEMS AND RESULTS Materials of the I International scientific-practical conference dedicated to the 100th anniversary of the FSBEI HE "GSTU named after academician MD Millionschikov": in 2 volumes. Grozny State Oil Technical University named after academician M.D. Millionschikova.

Shupik N.V. 2013. Improving reservoir pressure maintenance based on leading water flooding. Moscow. Oil and gas technology.

Zakharova EF, Pashanina O.D., Tronov V.P. 2003. Improving the reservoir pressure maintenance system at the Berezovsky field. Moscow. Electronic scientific journal "Oil and Gas Economy".

Zaurbekov Sh. Sh., Mintsaev M.Sh., Labazanov M.M., Shaipov A.A., Batukaev A.A. 2015. Improving the efficiency of well development in the oil fields of the Tersko-Sunzhenskoye oil and gas region. Grozny. Territory Neftegaz.

Zaurbekov Sh. Sh., Mintsaev M.Sh., Cherkasov S.V., Labazanov M.M., Shaipov A.A., Damzaev Z.M. E. 2015. Prospects for oil and gas potential and further areas of geological exploration within the TerskoSunzhenskoye oil and gas region. Grozny. Territory Neftegaz.

Zeigman, Yu.V. 2007. The operation of reservoir pressure maintenance systems in the development of oil fields: a training manual. USTU. - Ufa. Oil and gas business. 